\title{
Spleen, tedio y ennui. El valor indiciario de las emociones en la literatura del siglo XIX $^{1}$
}

\author{
María do Cebreiro Rábade Villar \\ Universidad de Santiago de Compostela
}

\section{RESUMEN}

El artículo se propone explorar las implicaciones semánticas del concepto de tedio a través de un análisis comparado de la novela Flavio, de Rosalía de Castro, y del cuento «The Man of the Crowd», de Edgar Allan Poe. Al igual que el spleen y el ennui, el tedio hispánico es un concepto emocional indisociable de la dinámica industrial instaurada en la ciudad moderna. En este sentido, puede leerse como síntoma de una profunda modificación en el horizonte estético y sociológico de la narrativa en la segunda mitad del siglo XIX.

Palabras Clave: Literatura comparada, Historia de las emociones, Edgar Allan Poe, Charles Baudelaire, Rosalía de Castro, Flavio, «The Man of the Crowd».

\section{Spleen, tedio and ennui. The Evidential Value of Emotions in XIX Century Literature}

\section{ABSTRACT}

This article explores the semantic implications of the concept of tedio through a comparative analysis of Rosalia de Castro's novel, Flavio, and Edgar Allan Poe's tale, «The Man of the Crowd». Like spleen and ennui, hispanic tedio is an emotional concept inseparable from the industrial dynamic of the modern city. In this sense, it can be read as a symptom of the profound modification of aesthetic and sociological aspects of narrative which took place in the second half of the XIX century.

Key words: Comparative Literature, History of Emotions, Edgar Allan Poe, Charles Baudelaire, Rosalía de Castro, Flavio, «The Man of the Crowd».

${ }^{1}$ Artículo vinculado al proyecto de investigación «Un análisis de la obra narrativa de Rosalía de Castro: fundamentos teóricos y metodológicos» (10 PXIB 204239 PR), del Plan Gallego de Investigación de la Xunta de Galicia. 
Reinhardt Koselleck, principal teórico de la denominada historia de los conceptos (Begriffsgeschichte), mostró en su obra la importancia de examinar las implicaciones semánticas e ideológicas del léxico en la emergencia de la modernidad (Koselleck, 2002). Los estudios literarios podrían beneficiarse de una de las principales enseñanzas de la Begriffsgeschichte: la historia es una construcción compleja en la que a menudo los fenómenos se entretejen de un modo sutil con las palabras. Afirmar que la historia no sólo se compone de hechos, sino también de conceptos, obliga a examinar con detalle el sustrato de conocimiento y experiencia que cobra forma en la expresión verbal, y de un modo privilegiado en la expresión literaria. Con los nombres de Schwermut, spleen, tedio, noia, mal de vivre, kedsomhed, Langweite o ennui la literatura de los siglos XVIII y XIX reconoció una forma emergente de sensibilidad parcialmente diferenciada de la melancolía. Situado a medio camino entre la tristeza y el aburrimiento, el tedio nombra un continuo emocional y estético estrechamente vinculado al mal de siglo y a la conciencia de la moderni$\mathrm{dad}^{2}$. En su estudio sobre el ennui, George Steiner reconocía la complejidad léxica y semántica del concepto:

El motivo que quiero precisar es el del ennui. «Aburrimiento» no es una traducción adecuada, ni tampoco Langweite, excepto, quizá, en Shopenhauer; la noia se aproxima mucho más. Tengo en mente múltiples procesos de frustración, de désouvrement acumulativo. Energías roídas hasta la rutina a medida que aumenta la entropía. El movimiento o la inactividad repetidos, cuando se prolongan lo suficiente, segregan un veneno en la sangre, un torpor ácido. Letargia febril; la náusea amodorrada (descrita con tanta precisión por Coleridge en la Biographia Literaria) del hombre que falla un escalón en la escalera: hay muchos términos e imágenes aproximados. El uso del spleen por Baudelaire es el que más se aproxima: transmite el parentesco, la simultaneidad de la espera exasperada, vaga —ipero de qué? - con el desgarro gris (Steiner, 1977: 20).

El fragmento citado nos previene del riesgo del nominalismo. Es tal la riqueza de las connotaciones asociadas a este conjunto sensible que tratar de caracterizarlo implicará antes un ejercicio de analogía que un ejercicio de discriminación. Desde el punto de vista etimológico, la palabra ennui ha sido emparentada con la expresión latina «esse in odio» ${ }^{3}$. Por su parte, spleen es palabra de origen inglés, a su vez procedente del griego antiguo $\sigma \pi \lambda \eta \dot{\eta}$ splèn, término médico relacionado con la teoría de los humores corporales. Debe tomarse en consideración, además, que los términos spleen y ennui, a pesar de

${ }^{2}$ En relación con la melancolía, es ya clásica la monografía de Klibansky, Panofsky y Saxl (1964), aunque su tratamiento iconológico de la acedia ha sido parcialmente objetado por Agamben (1977). La melancolía ha sido vista también como forma discursiva (Huguet, 1984). Desde el punto de vista de la filosofía estética, resultan valiosas las monografías de Bartra (2004) y de Svendsen (2006).

${ }^{3}$ Véase Kuhn (1976: 5). La importancia del ennui en la literatura occidental ha llevado a algunos autores a elegirlo como marcador historiográfico (Jonard, 1998). 
su origen respectivo, son a menudo intercambiables en los autores de habla inglesa y francesa.

Por analogía había procedido Ramón Joaquín Domínguez, cuando en su Diccionario nacional o gran diccionario clásico de la lengua española (1848) establecía un paralelismo semántico entre el tedio y el spleen, vinculados ambos al cansancio moral y al desprecio por la vida. En los estudios literarios ingleses y franceses el análisis de estos términos y de los conceptos a ellos asociados ha permitido dibujar el clima intelectual y sentimental de determinadas épocas. Del mismo modo, una caracterización del tedio hispánico puede ayudar a revelar algunas de las implicaciones históricas y estéticas de la literatura del siglo XIX, explorando los valores que le han sido asignados por algunos autores y el modo en que los sentidos que porta lo convierten en síntoma de un determinado momento cultural ${ }^{4}$.

De las citadas reflexiones de Steiner es posible inferir, además, que el spleen de Baudelaire es una de las formas literarias más afortunadas de la gama de emociones a la que estamos aludiendo, tanto por su capacidad de condensación como por su valor históricamente indiciario ${ }^{5}$. Al reconocimiento de la centralidad de Baudelaire en el canon de la literatura y de la sensibilidad moderna ha contribuido, sin duda, la obra del crítico Walter Benjamin, responsable directo de una serie de lecturas que vinculan el spleen y el ennui con las condiciones propias de la ciudad industrial ${ }^{6}$. El tedio, afección de naturaleza urbana, sería la enfermedad propia del paseante (flâneur), que ya no es capaz de procesar la vida metropolitana como un todo, sino como un complejo múltiple y fragmentario de sensaciones. Del mismo modo, los nuevos ritmos urbanos originarían una profunda modificación de los límites perceptivos del sujeto. El tedio experimentado por el flâneur sería al mismo tiempo causa y consecuencia de una profunda crisis de la sensibilidad moderna, que la literatura expresa a menudo bajo la forma de un embotamiento sensitivo. La figura del paseante melancólico ha dado paso a valiosas reflexiones en ámbitos tan diversos como la crítica de la modernidad, la sociología de la cultura, la teoría estética, la historia de las emociones, la cartografía cultural o el urbanismo.

\footnotetext{
${ }^{4}$ Entendida la ficción, al modo del «segundo Wittgenstein», como un tipo específico de juego de lenguaje, la vecindad semántica entre el tedio, el spleen y el ennui permitiría hablar de un aire de familia entre estos términos. Véase, para los conceptos de «Juegos de lenguaje» y «aire de familia» Wittgenstein (1988).

${ }^{5}$ En esta lectura del tedio como síntoma o indicio de la modernidad me atengo en buena medida a lo que Carlo Ginzburg (1989) ha venido denominando «paradigma indiciario».

${ }^{6}$ Walter Benjamin analizó el spleen en «Sobre algunos temas en Baudelaire»» (1939), «Zentralpark» (1940), «El París del Segundo Imperio en Baudelaire», así como en los capítulos dedicados a Baudelaire y al spleen en el inacabado Libro de los Pasajes (1927-1940). Pero el desarrollo de las categorías melancólicas en la obra de Benjamin, y su vinculación con los escenarios metropolitanos y con la figura del flâneur, deben también mucho a sus lecturas de Poe. Véase, a este respecto, Cunningham (2009).
} 
A través de un análisis comparado de algunos textos de Baudelaire, Edgar Allan Poe y Rosalía de Castro, trataré de mostrar el fondo común que, pese a las diferencias linguiísticas y culturales, late en ciertos autores de la segunda mitad del siglo XIX. Esta mirada de conjunto, proyectada sobre un ámbito literario supranacional, pretende reforzar una concepción historiográfica menos dependiente de las dinámicas de explicación basadas en los conceptos de influencia, adelanto o atraso. El surgimiento de un léxico emocional común al corpus examinado muestra, por una parte, que la articulación de nuevas experiencias sensibles puede ser leída como un síntoma de las nuevas condiciones vinculadas al proceso histórico de la modernidad y, por otra parte, que la respuesta literaria a estas condiciones fue en buena medida, y a pesar de las diferencias de matiz, un fenómeno de carácter global.

Una perspectiva como esta pretende reforzar, además, la necesaria reubicación de la producción narrativa de Rosalía de Castro, tarea crítica de la que en los últimos años han participado especialistas como Catherine Davies, Kathleen March, Lou Charnon-Deutsch, Susan Kirkpatrick o Marina Mayoral. Mayormente conocida y valorada como poeta, las novelas de Rosalía de Castro siguen demandando un proceso de actualización crítica que reconozca su papel en la forja de una nueva sensibilidad, en buena medida ya distante del romanticismo. Lo cierto es que la dedicación de la autora a la narrativa no fue un empeño marginal. Así lo demuestran obras como La hija del mar (1859), Flavio (1861), Ruinas (1866), El caballero de las botas azules (1867) y El primer loco (1880), estampas costumbristas como El cadiceño (1866), relatos breves como Conto gallego (1903) y otras incursiones prosísticas, por veces no ajenas al marco ficcional del relato epistolar como Las literatas (1865). Debido a su carácter en cierta medida descentrado con respecto al canon del XIX hispánico, las novelas rosalianas permiten problematizar categorías críticas fundacionales de la historiografía decimonónica tales como «romanticismo», «realismo», «costumismo» o, en el plano de los géneros literarios, «novela sentimental»y «folletín».

Resulta innegable que la narrativa de Castro participa de algunas de las principales convenciones de la literatura decimonónica. Se acogió claramente al molde genérico del folletín en sus novelas Flavio y Ruinas, y trató en su obra el modo en que las nuevas condiciones de producción editorial transformaron la circulación de los libros de ficción en la segunda mitad del siglo XIX ${ }^{7}$. Sin embargo, el tratamiento que la autora confiere a las emociones en su novelística difiere notablemente del canon sentimental propio de la novela por entregas. Este proceso se halla sin duda muy ligado a la irrupción de las nuevas ideas sobre la imaginación y la fantasía, que hacen entrar en crisis el antiguo paradigma mimético de la representación literaria, y de las que participará en buena medi-

\footnotetext{
${ }^{7}$ Sobre este último aspecto, véase Lozano de la Pola (2008) y Fernández (2005), que sigue de cerca la sociología literaria de Pierre Bourdieu.
} 
da su obra narrativa. No es de extrañar que a menudo en sus novelas se establezca una correlación explícita entre quienes sienten y quienes escriben ${ }^{8}$. Esta correlación entre sentimiento y creación verbal abre horizontes de pensamiento y percepción inéditos hasta el momento y permite establecer una compleja teoría literaria del sentir. El vínculo entre historia de las emociones y teoría de la ficción, en cierta medida todavía inexplorado, promete arrojar nuevas perspectivas en el estudio de la novela decimonónica9

Aplicada al análisis de la novela del siglo XIX, la historia de las emociones permite vislumbrar además la función de ciertos términos que trascienden el valor tradicionalmente concedido al léxico de lo sensible en la ficción moderna. Lejos de circunscribirse al ámbito de lo sentimental, entendido como reino de la pura efusión lírica, los conceptos emocionales portan a menudo significados desestabilizadores, tanto desde el punto de vista estético como desde el punto de vista sociológico. A esta luz, el tedio se revela como un concepto que porta una fuerte carga simbólica, toda vez que en él confluyen al menos tres órdenes de experiencia: a) el intelectual o cognitivo; b) el estético o sensitivo y c) el político o ideológico. Es digno de ser notado el hecho de que en los tres órdenes la función del tedio sea negativa, pues señala precisamente la incapacidad del sujeto para conocer, para sentir y para actuar. En este sentido, su expresión literaria sería indisociable de una fisura en el orden de la representación poética y narrativa, fisura presente, aunque con distintas modulaciones, en Baudelaire, Edgar Allan Poe y Rosalía de Castro. El spleen, el ennui y el tedio pueden ser vistos como síntomas de una concepción ambigua de la modernidad, proceso histórico que los tres escritores consideraron tan inevitable como problemático. Conscientes de la lógica de las nuevas relaciones sociales, defensores de las nuevas formas literarias y partícipes, tal vez a su pesar, en el nuevo régimen de la profesionalización de la escritura, puede afirmarse que Baudelaire, Poe y Castro fueron a la vez modernos y antimodernos ${ }^{10}$.

${ }^{8}$ Es significativo que tanto en Flavio como en La hija del mar los protagonistas masculinos y femeninos sean caracterizados reiteradamente como poetas. Y es ya convención crítica subrayar el carácter metaliterario de El caballero de las botas azules. Véase en este sentido Gullón (1986).

${ }^{9}$ En el análisis de la interacción entre teoría de la imaginación y sensibilidad, para el período comprendido entre la Antigüedad griega y el siglo XVIII, es sumamente valioso el artículo de Serés (1994).

${ }^{10}$ Tanto en el término «antimodernos» como en su caracterización, parto de Compagnon (2007). Su estudio sobre la relación dialéctica entre modernidad y antimodernidad, que el autor aborda explícitamente en el siguiente pasaje: «los verdaderos antimodernos son también, al mismo tiempo, modernos, todavía y siempre modernos, o modernos a su pesar. Baudelaire es el prototipo, su modernidad—él fue quien inventó la noción-es inseparable de su resistencia al 'mundo moderno' [...] Los antimodernos—no los tradicionalistas por tanto, sino los antimodernos auténticos-no serían más que los modernos, los verdaderos modernos, que no se dejan engañar por lo moderno, que están siempre alertas»(Compagnon, 2007: 19). 


\section{FLAVIO Y «THE MAN OF THE CROWD»}

Es conocida la estrecha filiación entre Poe y Baudelaire. El francés dedicó al americano numerosas menciones, notas y ensayos, además de traducir y compilar sus cuentos. Y aunque en principio no hay testimonios explícitos de un influjo de Baudelaire sobre Rosalía de Castro, en su epistolario deja constancia de su aprecio por Poe. En una carta dirigida a su marido Manuel Murguía, la autora escribe: «He leído ayer un cuento de Poe, precioso aunque sencillo. Allí comprenderás que era poeta. Otro que he leído de él, de un género opuesto, se parece al modo de escribir de Larra» (Castro, 1982: 535). El carácter mutilado de la carta, así como la ausencia de menciones más explícitas a la obra de Poe, son factores que impiden saber a ciencia cierta a qué dos cuentos podría referirse Castro. Pero es posible aventurar que uno de ellos fuese «La semana de los tres domingos», publicado el 15 de febrero de 1857 en El Museo Universal, revista con la que habían colaborado tanto ella como su marido, y en la que llegaría a publicar por entregas su novela Ruinas. Desdicha de tres vidas ejemplares (1866).

En su fundacional Edgar Allan Poe in Hispanic Literature (1934), John E. Englekirk había defendido que el primer cuento de Poe traducido al castellano era «Three Sundays in a Week». A su vez, Englekir se basaba en el estudio American Literature in Spain (1916), de John Langley Ferguson, que afirmaba que el cuento se trataba de una versión directa del original inglés. Pero en una nota reciente, Juan Gabriel López Guix (2009) revocaba de forma convincente estos dos presupuestos. En primer lugar, demuestra que «La semana de los tres domingos» se trata de una versión indirecta hecha a partir de una traducción francesa de Léon de Wailly. En segundo lugar, da noticia de un cuento de Poe traducido con anterioridad a «La semana de los tres domingos». En efecto, en el primer número de El Correo de Ultramar (3-9 de enero de 1853) había aparecido ya una versión del cuento «A Tale of the Ragged Mountains» («Una aventura en las montañas Rocheuses»). Esta versión aparece firmada con la leyenda: «Traducción d'Edgard Poe, por Carlos Baudelaire». Aquí puede hallarse la clave para la localización del segundo cuento leído por Rosalía de Castro. Y de paso, tal vez la documentación de la única relación literaria, aunque indirecta, entre la autora gallega y Baudelaire.

Sea cual sea la trama explícita de relaciones literarias entre los tres autores, el interés de Rosalía de Castro por Edgar Allan Poe resulta revelador de una búsqueda literaria común, que la autora hace extensible a Larra, y que debería ser tomada como acicate para una más ajustada ubicación del XIX hispánico en el horizonte de la primera modernidad literaria europea. En la medida en que no se trata aquí de rastrear la influencia directa de Poe sobre Castro, sino más bien de subrayar lo que Darío Villanueva (1991), en una de sus aproximaciones a la literatura comparada, ha denominado «polen de ideas», 
me centraré en mostrar la afinidad temática y estilística que comparten el cuento de Poe titulado «The Man in the Crowd», publicado simultáneamente en las revistas Atkinson's Casket y Burton's Gentleman's Magazine, en el mes de diciembre del año 1840, y las descripciones urbanas de los capítulos XXVI y XXVII de la novela Flavio, publicada por entregas en La Crónica de Ambos Mundos en el año 1861.

El cuento de Poe, traducido al francés por Baudelaire, y estímulo declarado de Le Peintre de la vie moderne (1863), ha sido objeto de múltiples aproximaciones críticas. Se ha subrayado, por ejemplo, su importancia en la conformación de una narrativa fundamentada en la forma espacial o el modo en que las categorías de la percepción acústica y auditiva establecen una correlación entre legibilidad literaria y legibilidad del espacio urbano (Hayes, 2002). En cambio, apenas ha sido objeto de atención la modulación emocional del relato, y ello a pesar de que los elementos anímicos son presentados por el narador como estímulos directos de la acción. Al comienzo, el protagonista se define a sí mismo como convaleciente de una enfermedad que no se especifica, aunque la polaridad dibujada entre el ennui que lo había mantenido alejado de la actividad y la exaltación febril que incita al intelecto a interesarse por todo permite al lector conocer casi desde el principio la importancia de su carácter en el desarrollo del cuento:

Not long ago, about the closing in of an evening in autumn, I sat at the large bowwindow of the D... Coffee-House in London. For some months I had been ill in health, but was now convalescent, and, with returning strength, found myself in one of those happy moods which are so precisely the converse of ennui-moods of the keenest appetency, when the film from the mental vision departs-achlus os prin epeen- and the intellect, electrified, surpasses as greatly its everyday condition, as does the vivid yet candid reason of Leibnitz, the mad and flimsy rhetoric of Gorgias. Merely to breathe was enjoyment; and I derived positive pleasure even from many of the legitimate sources of pain. I felt a calm but inquisitive interest in every thing. With a cigar in my mouth and a newspaper in my lap, I had been amusing myself for the greater part of the afternoon, now in poring over advertisements, now in observing the promiscuous company in the room, and now in peering through the smoky panes into the street. (Poe, 2000: 255).

Resulta iluminador confrontar este párrafo con el arranque del capítulo XXVI de la novela Flavio de Rosalía de Castro, fragmento situado estratégicamente en el meridiano de la novela. En el primer capítulo, el protagonista había abandonado la casa familiar en busca de una ampliación de su horizonte vital, impulsado por el lema universalista que da comienzo a la narración: «La verdadera patria del hombre es el mundo entero». Pero el ansia de libertad del héroe se verá progresivamente truncada por una serie de episodios que desvelan el carácter siempre paradójico e inestable del proceso de construcción de la individualidad. En el pasaje que nos disponemos a citar, Flavio se encuentra en el momento más crítico de su aventura. Después de algunos in- 
cidentes adversos, cree haber perdido el favor de la joven Mara, a quien corteja. La siguiente descripción es sintomática de su estado de ánimo:

Una lluvia menuda y penetrante caía sobre la ciudad de..., triste y sombría como el sepulcro. Era la hora del crepúsculo cuando Flavio atravesaba sus calles desiertas y mudas como el silencio, sin que nada viniese a arrancarle de su mal humor y de su abatimiento.

$\mathrm{Al}$ cruzar aquellas calles, enlodadas y angostas; al contemplar aquellas casas de abigarrado color, que parecía iban a derrumbarse las unas sobre las otras; al ver el pequeño pedazo de cielo que las cubría, encapotado y sombrío, tanto que podía creerse no llegaría jamás a iluminarlo un sol claro y transparente, el corazón de Flavio se oprimió y experimentó tedio y disgusto de la vida (Castro, 1982b: 156).

Esta será la primera aparición de la ciudad en la novela, cuya acción ha transcurrido hasta el momento entre pazos, bosques, posadas, caminos y quintas aldeanas. Aunque la tendencia crítica dominante ha sido interpretar Flavio como una alegoría de la desigualdad de los sexos (García Negro, 1986), no debieran descartarse otras lecturas. Además de representar críticamente ciertas convenciones sociales, y seguramente en confluencia con este objetivo, la novela supone una puesta en escena de la crisis de la sociedad rural, así como de sus relaciones de antagonismo con el mundo urbano. Es sabido que el problema de la propiedad campesina atraviesa el siglo XIX en España, y hay razones sobradas para interpretar ciertos episodios de la novela como una toma de posición explícita a favor de los derechos del campesinado. Desde las primeras páginas de la novela quedará claro el origen social de Flavio: una hidalguía semirural cuyo desclasamiento condiciona en buena medida la ambigüedad de su conducta. Hasta el capítulo XXVI el protagonista ha sido presentado bajo la tópica roussoniana del buen salvaje, aunque como veremos más adelante esta presentación tiene mucho de engañoso. El propósito de la autora es mostrar el tránsito que conduce desde el estado originario (vale decir, arcádico) de Flavio hacia el contexto civilizatorio de la vida urbana para terminar subvirtiendo la misma idea de una «evolución moral» del personaje. A esta luz, y como tendremos ocasión de mostrar más adelante, la novela se dibuja como un contra-Bildungsroman.

En términos de la experiencia de la lectura, la entrada de la ciudad en el relato resulta tan súbita para Flavio como para los receptores. Tal vez esta extrañeza permita explicar mejor el ánimo del personaje. Malhumor, abatimiento, opresión, tedio y disgusto de la vida son sus respuestas a la configuración de la ciudad. En el párrafo citado, su carácter sombrío la hace aparecer ante sus ojos como un sepulcro, al modo en que en Les Fleurs du mal Charles Baudelaire compara París con un cementerio (LXXV, «Spleen I»):

Pluviôse, irrité contre la ville entière,

De son urnne à grands flots verse un froid ténébreux

Aux pâles habitants du voisin cimetière

Et la mortalité sur les faubourgs brumeux (Baudelaire, 1975a: 72).

Revista de Literatura, 2012, vol. LXXIV, n. ${ }^{\circ}$ 148, 473-496, ISSN: 0034-849X, doi: 103989/revliteratura.2012.02.310 
En Rosalía de Castro y en Baudelaire la bruma y la lluvia contribuyen a desdibujar el espacio descrito, en un locus retórico que ha sido observado por muchos teóricos del spleen, del tedio y del ennui. Más relevante puede ser preguntarse en qué medida lo crepuscular, lo sombrío y lo neblinoso están sugiriendo la entrada en la literatura de nuevas categorías perceptivas. El segundo párrafo del capítulo XXVI de Flavio, arriba citado, introduce hasta dos verba sentiendi: ver y contemplar. $\mathrm{Y}$ ambas acciones son directamente relacionadas con el hastío. El paseante literario no se define como tal únicamente por sus desplazamientos en el espacio urbano, sino también porque, en sus paseos, mira. Pero lo que ve (y, como veremos más adelante, lo que escucha) le conduce inevitablemente al tedio. Este fastidio del corazón, vinculado al sentido de la vista, y más en concreto a una visión nublada, describe nuevos trayectos en la configuración del mapa perceptivo.

Como el nombre del café londinense desde el que el narrador de Poe contempla la ciudad, Rosalía de Castro usa los puntos suspensivos como representación formal del escenario urbano. En Poe y en Castro esta apuesta es, sin duda, una decantación por el carácter abstracto de los espacios invocados, unida al misterio y a la poética del asombro que introduce en los relatos ese principio de incertidumbre. Basándose en el epistolario de la autora, es posible identificar el referente textual de estos capítulos de Flavio con la ciudad de Santiago de Compostela. En su edición de la novela, Mauro Armiño remite a una carta de Rosalía, fechada en Santiago, el 16 de diciembre de 1861 y dirigida a su marido Manuel Murguía, en donde Santiago es comparada también con un sepulcro:

En Santiago hace un frío espantoso y apareció a mis ojos tal cual lo he descrito en Mauro. Jamás he visto tanta soledad, tanta tristeza, un cielo más pálido [...] Por ahora me encuentro aquí en extremo descontenta. Santiago no es ciudad, es un sepulcro. No vayas a creer, sin embargo, que ya tengo melancolía, que voy a enfermar (Castro, 1982b: 534) ${ }^{11}$.

Rosalía de Castro establece en esta carta una correspondencia entre la angostura del espacio físico y la angustia del corazón, entre la enfermedad del alma (melancolía epistolar, que será fastidio novelesco en Flavio) y la experiencia del paisaje urbano. La figura retórica de la evidentia, el ad oculos mostrare de la oratoria clásica («apareció a mis ojos») refuerza una vez más la idea de un tedio que entra por la vista: «Jamás he visto tanta soledad».

\section{EMOCIÓN Y ESCRITURA EN LA LITERATURA MODERNA}

La lexicalización de la metáfora del corazón como asiento del sentir nos

\footnotetext{
${ }^{11}$ En la misma página el editor, bajo la palabra Mauro, aclara: «al parecer fue el primer título pensado para Flavio».
} 
impide percibir la complejidad de sus usos en la literatura del siglo XIX. Por ceñirnos a las novelas y a los ensayos de Rosalía de Castro, a menudo el corazón condensa las actividades perceptivas, sensitivas e intelectivas del ser humano. Mas lo hace de un modo a menudo misterioso. Así, en el capítulo XIV de El caballero de las botas azules, la narradora describe en los siguientes términos al Duque de Gloria: «Su corazón y su pensamiento son una inmensidad en donde la más penetrante mirada no encuentra límites. ¿Quién sabe lo que hay allí?» (Castro, 1982a: 458). O, de un modo todavía más explícito, y como prueba de que la incognoscibilidad del corazón no es propia únicamente del caballero, sino también de la cándida Mariquita: «Toda la experiencia de los hombres no basta muchas veces para adivinar siquiera los secretos de un corazón inocente» (Castro, 1982a: 409). Incognoscibilidad del corazón que parece devolvernos al final de «The Man of the Crowd» de Edgar Allan Poe: «The worst heart of the world is a grosser book than the 'Hortulus Animae,' and perhaps it is but one of the great mercies of God that «er lasst sich nicht lessen» (Poe, 2000: 262).

El corazón moderno opera, pues, como expresión de la ambigüedad y del vacío. Así lo sugiere el título de Mon coeur mis à nu, diario fechado en 1887 que Baudelaire escribió bajo el influjo de las observaciones de Poe en Marginalia. Pues aunque ha sido notado con frecuencia el carácter anti-sentimental de las propuestas literarias de Poe (factor especialmente enfatizado por Baudelaire), no es menos cierto que los procesos emocionales ocupan un papel central en su poética. Ocurre que la irrupción en su obra de una sensibilidad abiertamente moderna implicará un proceso muy consciente de transvaloración de los contenidos anteriormente asignados al sentir. Sobre todo ello el autor se detiene con detalle en los escritos dedicados a la teoría poética. Citaré, por su oportunidad en este contexto, aquél que estimuló el citado diario de Baudelaire, reflexión originariamente publicada en el Graham's Magazine, en enero de 1848:

If any ambitious man have a fancy a revolutionize, at one effort, the universal world of human thought, human opinion, and human sentiment, the opportunity is his own-the road to immortal renown lies straight, open, and unencumbered before him. All that he has to do is to write and publish a very little book. Its title should be simple-a few plain words- «My Heart Laid Bare.» But-this little book must be true to its title.

Now, is it not very singular that, with the rabid thirst for notoriety which distinguishes so many of mankind-so many, too, who care not a fig what is thought of them after death, there should not be found one man having sufficient hardihood to write this little book? To write, I say. There are ten thousand men who, if the book were once written, would laugh at the notion of being disturbed by its publication during their life, and who could not even conceive why they should object to its being published after their death. But to write it-there is the rub. No man dare write it. No man ever will dare write it. No man could write it, even if he dared. The paper would shrivel and blaze at every touch of the fiery pen (Poe, 1984: 1423). 
Poe desafía a los escritores ambiciosos a escribir un libro que juzga de ejecución imposible. Un libro que osase ofrecer un corazón al desnudo sería, para el autor, tan fácil de publicar como difícil de escribir. Pero el talento de Baudelaire, tan proclive a la hybris, quiso desafiar esa certeza, escribiendo un diario íntimo que ha de leerse al mismo tiempo como homenaje y subversión. Aparece aquí, explícitamente formulado, el motivo literario de la correlación entre el sentir y el escribir, ligada al tópico romántico de la inefabilidad. En buena medida, la metáfora del corazón como libro explica algunas de las principales paradojas de la literatura moderna, situada entre la aspiración a la infinitud y la conciencia de los límites. Lo que el Poe de Marginalia y el Baudelaire de Mon coeur mis à $n u$ ponen de relieve es que la tensión entre totalidad y finitud no afecta únicamente a la transformación moderna de la racionalidad, sino también a la emergencia de un nuevo régimen emocional. La imagen del papel que se arrugaría y ardería a cada toque ardiente de la pluma, que finaliza el citado aforismo de Poe, hace pensar en uno de los pasajes más metapoéticos de Follas Novas: «Mollo na propia sangre a dura pruma / rompendo a vena inchada / E escribo..., escribo..., ¿para que?» (Castro, 2004: 51). Y sobre la interpenetración entre teoría del poema y teoría del relato en ambos autores no estará de más recordar que, en su carta a Murguía, refieriéndose a los dos cuentos que había leído, la autora escribió: «Allí comprenderás que era poeta».

En las novelas de Rosalía de Castro son caracterizados con gran profusión de detalles los procesos del imaginar, del recordar, del conocer y del sentir, así como sus complejas interrelaciones. En última instancia, todos estos procesos hacen del corazón su inestable morada. Cuando en El caballero de las botas azules el Duque de Gloria trata de convencer a Melchor de la necesidad de que reconquiste a Mariquita, este, desconcertado, le responde: «Esas ideas me confunden y lo que veo al través de ellas parece darme alguna esperanza, mientras por otro lado deja vacío dentro de mi corazón un hueco que yo llenara con ilusiones y creencias bien distintas por cierto» (Castro, 1982a: 512-513). Este vacío del corazón prefigura en verdad un giro importante en la expresión literaria del siglo XIX. Desprovisto de contenido, el corazón desnudo es la imagen misma de la reflexividad, de un vuelco de la representación literaria hacia la tierra incógnita de lo íntimo.

La vida exterior, entendida como correlato objetivo de la vida interior, será uno de los fundamentos del capítulo XXVI de Flavio. Volcados el sentir y los sentidos del protagonista hacia el escenario urbano, el propósito fundamental de la narración no será sólo la captación detallada de la fisonomía de la ciudad, sino mostrar el modo en que los pasos del caminante resuenan tanto en las calles como en su ánimo:

Bajo los angostos soportales, apiñados los transeúntes para preservarse de la lluvia, semejaban silenciosas y medrosas sombras que llegaban y huían consecuti- 
vamente; una luz melancólica, que parecía iluminar un subterráneo, dejaba percibir, en el fondo de aquella especie de tumbas, alguna vieja durmiendo amorosamente en compañía de un soberbio Micifuz, o el rubicundo mancebo, que con sus grandes, manos, lastimosamente laceradas por los fríos de invierno, envolvía pacíficamente y con suma escrupulosidad las telas que curiosos compradores habían hecho desdoblar en vano (Castro, 1982b: 156-157).

El párrafo anuncia una sutil transformación de la perspectiva narrativa que se manifestará con plenitud en el siguiente capítulo. La mezcla de ironía y de ternura empleada en la breve caracterización de la vieja que duerme bajo los soportales «en compañía de un soberbio Micifuz» obedece a un descriptivismo urbano distante de la retórica romántica ${ }^{12}$. Por no hablar del mancebo que dobla y desdobla sus telas ante los curiosos compradores. La melancolía sigue planeando por entre las calles, llenas de sombras, pero el dinero ha hecho su entrada en esta escena, determinando por completo un cambio de orientación en el discurso.

La representación de las actividades comerciales en la literatura moderna es a menudo sintomática de un cambio de sensibilidad que merece la pena observar en detalle. En este contexto, la referencia al frío que lastima las manos del joven vendedor es uno esos fogonazos de crítica social que iluminan sombríamente numerosos pasajes de la obra de Rosalía de Castro. Los transeúntes empiezan siendo caracterizados como figuras espectrales («semejaban silenciosas y mederosas sombras que llegaban y huían consecutivamente») y una vez la luz melancólica ilumina los soportales-tumbas pasan a ser caracterizados como «curiosos compradores» indiferentes a la suerte del mancebo. Esta atmósfera espectral, tan querida a Rosalía de Castro, viene a reforzar a su vez el carácter fantasmático de las relaciones en la ciudad moderna. En palabras de David Cunningham, que sigue de cerca la obra del sociólogo Georg Simmel: «la metrópoli constituye ese nuevo mundo urbano en el que la experiencia social viene configurada o producida por el intercambio» (Cunningham, 2009: 77).

\section{Nuevos SUJETOS URBANOS. LA REPRESENTACIÓN DE LA MULTITUD}

En el capítulo XXVI de Flavio el orden narrativo hacía confluir la expresión del disgusto con la economía del dinero y la atmósfera espectral con el sentimiento de vacío. La ficción mostraba así el modo en que la experiencia moderna surge como resultado de una integración de aspectos inteligibles y sensibles, experiencia que, en último término, tiende a cuestionar la distinción

${ }^{12}$ Sin embargo, es obligado señalar que cuando menos en el ámbito angloamericano, el romanticismo literario había empezado a incorporar una atención demorada a las condiciones productivas de la vida social, como lo demuestra Gilmore (1985: 12). 
entre objetividad y subjetividad. En buena medida, la descripción urbana no sólo presupone la presentación de nuevos escenarios, sino también la emergencia de nuevos sujetos.

La pregunta que surge en este contexto es de qué modo se va forjando literariamente lo que entendemos por individuo moderno, proceso extremadamente ligado al auge de la narrativa a lo largo del siglo XIX. Algunas de las respuestas a esta cuestión las encontramos en el capítulo XXVII de la novela, que va preparando el tránsito del héroe romántico al dandy y del dandy al flâneur. Veamos su arranque:

Al siguiente día se paseaba nuestro héroe por las calles de la ciudad, solitario, meditabundo y con el mismo desdén y abandono que si errara lentamente por las solitarias alamedas de su olvidado parque.

Al verle caminar con aquella lentitud cansada y negligente, al ver su rostro ojeroso y macilento, en el que se descubrían las huellas del insomnio, y sus cabellos medio en desorden, que el viento agitaba levemente bajo el ala de su sombrero, pudiera tomársele por alguno de esos hombres para quienes es aborrecible la nueva luz que cada día viene a iluminar su frente, ajada y marchita por la incontinencia y el desorden.

Y, en verdad, ¿qué era para él la vida en aquellos instantes? (Castro, 1982b: 170).

La soledad, el desdén, el abandono, la incontinencia, el desorden, la palidez, el insomnio y el desprecio por la vida son signos característicos del héroe romántico. Todas estas afecciones, inducidas por lo que Flavio juzga indiferencia de su amada, podrían leerse como síntomas del fastidio universal, definido por Sebold como aquel «conjunto de emociones contradictorias experimentadas por quien se compadece de las sufridas masas, cumple con los preceptos del culto religioso y busca el amor, y, sin embargo, se goza exquisitamente acariciando el dolor que le ahoga al verse abandonado por los hombres, por su Dios y por la mujer» (Sebold, 1989: 99). Ni siquiera faltaría, para confirmar la aparente adscripción del texto al régimen romántico, una mención a las «alamedas de su olvidado parque», a esos jardines con que el Romanticismo selló su alianza entre naturaleza y cultura. Diríase que la autora ha reunido en un solo fragmento todas las afecciones posibles del caballero doliente, brindándonos más una caricatura que una etopeya. Mas a medida que el texto avanza, el dolor romántico abre paso a una nueva modalidad del sentir, que enseguida se convierte en perplejidad de los sentidos:

El ruido de los carros, lecheras y vendedores, que no cesaban de aturdirle con sus voces discordantes y chillonas y de rogarle con sus mercancías, del modo más importuno y tenaz; el incesante ir y venir de las gentes, y el sonido penetrante de las innumerables campanas, entre las cuales algunas doblaban de un modo lúgubre y lastimero, causaron en Flavio una impresión desagradable que aumentó el sombrío humor que le devoraba. Sin saberlo, era un verdadero misántropo a quien la algazara y el ruido desagradaban por instinto, pues sólo podía vivir contento con sus eternos sueños, y hubo instantes en que pensó si la mayor parte de los hombres serían verdaderamente locos cuando podían resistir aquella agitación y 
movimientos no interrumpidos, aquellos rumores, discordes e incesantes, bajo cuya influencia parecían hallarse como en su principal elemento de vida y felicidad (Castro, 1982b: 172).

Obsérvese la curiosa inversión propiciada por la voz narrativa. No es el héroe de la novela, aquejado de tedio, quien se presenta ante los lectores como enfermo, sino la multitud que camina «con paso acelerado» y que, además de aturdir la vista, aturde el oído. En «Les Foules»(Le Spleen de Paris, XII), Baudelaire había mostrado que las posiciones del sujeto y de la multitud podían ser intercambiables: «Multitude, solitude: termes égaux et convertibles pour le poète actif et fécond. Qui ne sait pas peupler sa solitude, ne sait pas non plus être seul dans une foule affairée» (Baudelaire, 1975b: 291). Este es precisamente el caso de Flavio. Al no saber habitar su soledad, tampoco sabe estar solo entre la muchedumbre. A través de un hábil empleo de la focalización interna, Rosalía de Castro propicia una redistribución de las posiciones subjetivas. Lo que el flâneur, en su deambular, pone de relieve es no sólo su propia enajenación como individuo separado de la multitud, sino también la enajenación de una multitud capaz de hallar acomodo en el ritmo frenético propio de las «grandes poblaciones»:

Al ver a la multitud caminar con paso acelerado, como es costumbre en las grandes
poblaciones, y cuyo movimiento y agitación tanto contrastaba en aquellos instantes
con su desesperada calma, creía a todas aquellas gentes en un estado de inquietud
enfermiza y recelosa, y pensaba que aquellas altas casas, las unas tan cerca de las
otras, y aquellas revueltas y estrechas calles, que apenas dejaban paso al aire co-
rrompido que se infiltraba por ellas, debían hacer precisamente a los hijos de aque-
lla capital cobardes, pusilánimes, y su vida, corta y trabajosa (Castro, 1982b: 172).

La multitud que camina con paso acelerado es, desde su mismo título, uno de los elementos más presentes en «The Man of the Crowd». Del París de la Comédie humaine de Balzac a La Curée de Émile Zola, de la ciudad hormiguero de Les Fleurs du Mal a la multitud que pasaba por el puente de Londres de The Waste Land, pocos aspectos han determinado de un modo tan claro el trayecto hacia la modernidad narrativa como la representación de la muchedumbre. Este trayecto, uno de cuyos jalones más definitivos será el unanimismo de la narrativa experimental del siglo $\mathrm{XX}$, encuentra en el cuento de Poe uno de sus más singulares exponentes. En primer lugar, interesa el reconocimiento de una relación dialéctica entre individuo y multitud: en virtud de la observación generalizadora, la multitud emerge como unidad regida por relaciones de afinidad, pero es preciso descender al detalle para percibir su variabilidad interna:

At first my observations took an abstract and generalizing turn. I looked at the passengers in masses, and thought of them in their aggregate relations. Soon, however, I descended to details, and regarded with minute interest the innumerable varieties of figure, dress, air, gait, visage, and expression of countenance (Poe, 2000: 255-256). 
Esta variabilidad no atañe sólo a la indumentaria, a la expresión o a la fisonomía del rostro. Una de las cualidades más incisivas del protagonista del cuento es su capacidad para revelar el peso de una fuerte estratificación social en el escenario urbano. En efecto, no hay clase a la que el narrador no pase un minucioso e irónico examen. En un inacabable fresco humano, ante el lector desfilan comerciantes, abogados, rentistas, hombres de negocios, apátridas, empleados, rateros, tahúres, caballeros, obreras, prostitutas, borrachos, barrenderos, organilleros, artistas, pasteleros, recaderos, cargadores de carbón... Una monumental enciclopedia del ocio y del negocio, de la divagación, del hurto o de la explotación del hombre por el hombre. Una vez más, la respuesta del narrador es de orden sensitivo. La proliferación de estímulos conduce a la saturación de la vista y del oído: «and all full of a noisy and inordinate vivacity which jarred discordantly upon the ear, and gave an aching sensation to the eye» (Poe, 2000: 258). Esa es también la confusión de Flavio, cuya exposición a los sonidos de la ciudad lo había conducido casi a la sordera.

Pero a pesar de todas las analogías posibles entre Poe y Rosalía de Castro, la multitud de Flavio no es representada según estos principios de distinción interna y jerarquía. En la autora la multitud es a menudo simplemente masa, tal vez porque la representación unánime de la pluralidad porta en su narrativa un claro propósito de corte ideológico. Ha sido estudiada con detalle la relación de la autora con el ideario de Proudhon y de Krause y con la democracia radical del siglo XIX (Davies, 1987). Bajo esta perspectiva tal vez pueda comprenderse mejor el hecho de que en sus novelas la multitud sea concebida, bien como sujeto de las injustas condiciones propiciadas por la monetarización de la vida social, bien como agente de un futuro cambio social y político. La primera posibilidad se concretaba con nitidez en uno de los fragmentos citados de Flavio. El urbanismo angosto de la ciudad generaba por fuerza tipos humanos aquejados de debilidad moral y de vida «corta y trabajosa». En el capítulo anterior, el salvaje héroe no había dudado en sostener ante Mara la creencia de que «las ciudades son un infierno, en donde es necesario educar hasta el corazón». Para añadir, como conclusión: «y si esto es así, renuncio a civilizarme y prefiero vivir salvaje» (Castro, 1982b: 166). Pero en El caballero de las botas azules la multitud depone su carácter pasivo para mostrarse como de sujeto del cambio revolucionario. El siguiente pasaje, que ha sido concebido como extraña anticipación literaria de la Gloriosa, lo muestra claramente:

Y cuando allí llegaron los primeros, vieron ya que el palacio resplandecía de tal manera que semejaba un vasto incendio, y que desde los balcones se arrojaba a la muchedumbre multitud de pequeños objetos, que caían en torno a ella semejantes a una granizada interminable $[\ldots]$

Hubo con esto cabezas rotas, magullamientos, riñas..., vino la guardia... mas iquién contenía aquella oleada de furiosos? Los libritos encuadernados en terciopelo y 
con broches de oro encerraban un encanto irresistible para todos... ¡Cómo que eran tan lindos y se daban de balde! Las puertas del palacio se abrieron después de par en par, y comprendiendo la multitud que se abrían para ella, se precipitó dentro como una horda salvaje (Castro, 1982b: 564-565).

La multitud, ya plenamente despersonalizada, deviene en esta novela muchedumbre furiosa y horda salvaje. En Flavio el salvajismo era todavía la condición de quien precede o de quien renuncia a la civilización, identificada de modo inequívoco con la vida ciudadana. En uno de los combates dialécticos entre el protagonista y Mara, el héroe afirma: «Yo aborrezco el mundo... pero tú amas el mundo» (Castro, 1982b: 259). Y este será precisamente uno de los nudos del conflicto entre los personajes. Pero en El caballero de las botas azules los salvajes ya no serán quienes antecedan o rechacen el orden social, sino quienes se apresten a destruirlo. En cierto modo, se diría que $E l$ caballero de las botas azules, con sus desafíos paródicos y sus inversiones burlescas, comienza donde había terminado Flavio. Y el final de Flavio no es otro que un inesperado carnaval cortesano, que como todo carnaval acaba por sacar a la luz la verdadera naturaleza de los personajes.

No debe ser pasada por alto la querencia de la autora por lo carnavalesco. La farsa y la inversión pueden fácilmente ser interpretadas como crítica acerba al fundamento del nuevo contrato social. La novelística rosaliana muestra a menudo la alianza, tan inestable como opresiva, entre los rígidos convencionalismos de la vida social y la injusta artitrariedad instaurada por el libre comercio. En este contexto, la representación de la vida emocional del personaje alcanza un valor muy superior al que tradicionalmente le ha sido conferido. No es sólo que la persona aquejada por el tedio experimente determinadas sensaciones y sentimientos, sino que la presencia de una interioridad socialmente inadecuada en el entramado ficcional es capaz de desafiar como pocos aspectos el orden representativo convencional.

\section{TEDIO Y AZAR. LA NOVELA COMO CRÍTICA DE ARTE}

Al igual que en «The Man of the Crowd», el protagonista de Flavio, primero observador y luego paseante, desafía la normatividad social —es un extranjero que persigue a otro extranjero, deambulando entre la multitud- y el principio de productividad industrial. Frente a la laboriosidad regular del empleado, el flâneur no se rige por ninguna otra ley que el azar. La angostura del trazado urbano descrito por Rosalía no hace pensar en las grandes avenidas de París ni en las anchos paseos de Londres, pero en cambio acentúa lo que de laberíntico pueda haber en los desplazamientos del caminante ocioso. El azar resulta determinante para vincular el trayecto de Flavio a la noción moderna de deriva, iniciada por Poe y Baudelaire en el siglo XIX, reinterpretada por Walter Benjamin en la primera parte del siglo XX y culminada, 
ya en el escenario de la última vanguardia, por el situacionismo. Véase el peso del acaso en el siguiente pasaje:

Se vistió con desaliño, compuso apenas sus desordenados cabellos, y cuando la puerta se abrió, salió el primero y recorrió al azar toda la vieja ciudad. Ni buscó a nadie que le guiase a través del intrincado laberinto de las tortuosas calles, ni pensó en dirigirse hacia aquel o el otro punto; sin rumbo fijo, le era indiferente caminar hacia un lado o hacia el otro y recorrer los barrios más elegantes o los más sucios y ruinosos de la antigua ciudad. (Castro, 1982b: 171-172)

Primero, el descuido personal y luego, como síntoma externo de éste, la indiferencia ${ }^{13}$. Una indiferencia que, es digno de ser notado, tiene como repercusión primera la desorientación espacial y la pérdida del sentido de la jerarquía estética. El pasaje lo muestra a partir de un sutil tropo locativo que relaciona valores artísticos y puntos de la geografía urbana: a Flavio le da igual moverse hacia un lado que hacia otro o, siguiendo la metáfora espacial, hacia lo bello y elegante que hacia lo sucio y ruinoso. El saber estético del flâneur es un saber no jerarquizado, un saber que confunde centro y periferia. Pero al igual que Baudelaire, Castro está mostrando en este pasaje que todo paseo es un acto de lectura, una actividad de expectación o, como quería Francesco Carreri (2002), una práctica estética. Y lo que determina la modernidad del pasaje es la certeza de que esta expectación puede quedar truncada por la indiferencia, en un pulso de signo ambiguo entre el rechazo a la contemplación y lo que es digno de ser observado. Desde el punto de vista de la configuración de nuevos lectores en la narrativa del siglo XIX, resulta tentador comparar al Flavio que, desdeñoso, mezcla el centro con la periferia y lo viejo con lo nuevo con el lector moderno que, de modo vacilante, empieza a forjar nuevos caminos en el proceso de la interpretación literaria.

En todo caso, la salida del laberinto urbano, prefigurada en el párrafo siguiente, supondrá una nueva entrada del protagonista en el orden de la naturaleza:

Anduvo así mucho tiempo, sin pensar siquiera que había recorrido ya la mayor parte de la ciudad; saliéronle al encuentro, digámoslo así, inmensos y sombríos edificios, soberbias obras de arte que una generación eminentemente artista había levantado, y no lograron cautivar su atención, y siguió al acaso una sucia y angosta calle que desembocaba en los alrededores de la ciudad, que eran verdaderamente hermosos (Castro, 1982b: 172-173).

Por oposición a la naturaleza, el espacio urbano es definido como un espacio de opresión. La clave anímica era hasta ahora la falta de jerarquía entre centro y periferia, relacionada con la indiferencia ante lo bello o ante lo feo. El sentido estético del pasaje se acentúa cuando el narrador hace referencia

${ }^{13}$ Para la lectura sociocrítica de la ambivalencia y la indiferencia novelesca véase Zima (1980). 
explícita a lo que debería suscitar la atención de Flavio: las obras de arte. Esta falta de atención es característica del tedio, sentimiento que, en sutil aporía, podría definirse como «pasión desapasionada». El paseante, al desdeñar las obras de arte «que una generación eminentemente artista había levantado» rompe el orden civilizatorio de la sucesión histórica. En el debate entre lo bello del arte y lo sublime de la naturaleza, que había permeado la filosofía estética desde el siglo XVIII, Flavio se decanta por el encanto libre del paisaje de la periferia semirural. Ecos del sentimiento romántico de lo natural hermoso, vinculado a la inmensidad y al infinito, pueden hallarse en el siguiente párrafo:

Jamás había parecido al viajero tan hermosa la naturaleza; embriagóse con el aire puro que pasaba azotando su rostro; tuvo intenciones de besar la fresca hierba que hallaba a su paso, humedecer sus manos en el agua de los arroyos y correr como un loco por la pradera. Le pareció entonces que había vuelto de nuevo a la vida, al aire puro, a la hermosa libertad; y el recuerdo de Mara ya no fue entonces tan penoso para él y tan desconsolador (Castro, 1982b: 173).

El círculo que abría el capítulo XXVI de la novela parece haberse cerrado. Convertido en flâneur por su deambular errático y dandy en virtud de la crítica (acerba y nihilista, por cierto) a la escultura y a la arquitectura urbanas, el héroe romántico volvería en este pasaje idílico a su ser primero. Pero la amorosa comunión con la naturaleza no es sino una breve ilusión en el régimen emocional del personaje. En las cercanías de este locus amenus tiene lugar el entierro de una joven y la contemplación del cadáver y del cortejo fúnebre devuelven a Flavio la conciencia de su propia mortalidad, conciencia que anticipa su voluntad de atentar contra su propia vida. En el ya citado Diccionario nacional o gran diccionario de la lengua española, Domínguez había visto en tedio la antesala de la muerte autoinducida, al definirlo como un «estado de aversión natural a todo, como si se hubiera estragado el gusto de la vida, como el esplín de los ingleses que, llevado al estremo, conduce sin remedio al suicidio» (Domínguez, 1848: 1620). Pero ni tan siquiera esta salida trágica le será reservada al personaje. Cuando Flavio trate de ahogarse en el río luego de enrevesadas cavilaciones sobre el fantasma de la muerte y la futilidad de la existencia, un desconocido irrumpirá en la trama para impedirle cumplir con su destino trágico.

\section{UN FOLLETÍN TRUNCADO. LA DESTRUCCIÓN DEL PACTO EMOCIONAL}

Al fracasar como héroe romántico en virtud de un calculado recurso al Deus ex machina, a Flavio no le quedará ya sino fracasar también como amador. Luego de su intento de suicidio, se irá consumando lentamente el camino del personaje hacia la degradación moral. El párrafo final de la novela es implacable. El lector tiene noticia de que Flavio, luego de abandonar a Mara, 
contrae matrimonio con una mujer que es «vieja y horrible, pero tiene ocho millones de capital». Y cada vez que alguien le recuerda las penas pasadas, él se limitará a replicar, riendo: «Pero, amigos míos, no creáis que miento; aquí en donde me veis, esas pequeñas historias me han causado sus disgustillos en otro tiempo... No me arrepiento, sin embargo, y nunca está de más una historia para contar en la vejez...»(Castro, 1982b: 284).

La imposibilidad de escapar del tedio tal vez sea el sentido último de una de las sentencias más citadas de Walter Benjamin: «Cualquiera que sea la huella que el flâneur persiga, le conducirá a un crimen» (Benjamin, 1980: 56). Al igual que el extraño caminante de Poe, también el viajero de Rosalía de Castro viajaba hacia el crimen. En ambos casos, la razón última de su comportamiento parece ser tan insondable como su corazón. En la misma medida en que se relacionan soledad y multitud, en la ficción moderna se relacionan perseguido y perseguidor, castigo y crimen. La radical ambigüedad de «The Man of the Crowd» reside en que en él terminan por confundirse el narrador y el lector, el supuesto detective y el supuesto asesino. A este juego de apariencias y efectos se entregará también la novela rosaliana. ¿Cómo interpretar si no este sorprendente final, que obliga a releer la conducta del héroe a una luz distinta de la que hasta el momento se les había ido mostrando a sus lectores? Hasta la llegada del último capítulo, Flavio podría ser culpado por su naturaleza infantil e indomable, así como por haber restringido con sus continuas exigencias la libertad conquistada por el personaje femenino. Pero la voz narrativa, a menudo cómplice de la perspectiva de Mara, insiste con frecuencia en la sinceridad y autenticidad de sus emociones.

Del carácter subversivo del relato informa sobradamente el hecho de que los lectores hayan sido llevados a identificarse con un personaje que, en una inversión paródica del Bildungsroman, empieza por ser salvaje y termina por ser cínico. El final de la novela no puede sino truncar la esperanza, al comienzo incluso previsible, en una resolución favorable a la dignidad del héroe. Lo que significa, en último término, que la autora ha elegido violentar deliberadamente las expectativas de la lectura, alterando las reglas del melodrama y la sucesión de lances patéticos propia de la novela por entregas, que invitan a la identificación empática con el héroe. La ironía de la palabra «asuntillos», con que Flavio alude a su pasado emocional, obstaculiza de modo definitivo la posibilidad de una lectura inocente de cuanto ha sido expuesto ante el lector.

En este contexto el tedio desempeña un papel determinante. Su irrupción en la ficción sentimental anuncia que la resolución del conflicto novelesco no transitará por los lugares emocionales propios de la ficción sentimental, que van desde el desgarro por la separación hasta la reunión de los amantes. Al registrar el uso y las modulaciones de la palabra tedio, al ilustrar el modo en que se alía con ciertos espacios y con ciertas peripecias o al describir el régimen de relaciones sociales al que permanece asociado en la ficción, es posible mostrar su valor sintomático. Esta y otras tareas tal vez sirvan para co- 
rregir una tendencia señalada por Steiner en «El Gran Ennui», al constatar el hecho de que todavía «carecemos de historias del sentido interno del tiempo, del mudable compás que en la experiencia humana tienen los ritmos de la percepción» (Steiner, 1977: 15).

En alianza con la historia de los conceptos, la historia de las emociones permite vislumbrar lo que, en el terreno de la expresión sensible, ha de aguardar a ciertas configuraciones literarias para aflorar plenamente. ¿Sería posible hablar del tedio, tal y como en la actualidad lo conocemos y lo experimentamos, sin tener en cuenta lo que sabemos o sobre Madame Bovary? Responder afirmativamente implicará, con certeza, aventurarnos en el estudio pormenorizado de otros capítulos menos conocidos de la novela decimonónica española que, como la narrativa de Rosalía de Castro, aguardan todavía por una comprensión más ajustada.

\section{CODA}

Son varias las conclusiones que es posible extraer de esta confrontación entre los textos de Charles Baudelaire, Edgar Allan Poe y Rosalía de Castro. En primer lugar, la presencia de una estrecha correlación entre espacios y afectos. Tradicionalmente, el análisis del spleen y del ennui se vinculaba a la emergencia de una nueva temporalidad, determinada por el paso fugaz del flâneur y de los transeuntes. Sin negar el peso del sentimiento de la fugacidad en la caracterización de lo moderno, se hace cada vez más preciso examinar el modo en que la ficción literaria ha tendido a vincular la expresión afectiva con la contrucción espacial. En el caso del tedio, elementos visuales como la bruma, el humo o la lluvia superan claramente la función de decorado, acompañando la expresión del hastío de tal modo que se dirían casi indisociables de él. Pero en la medida en que el hastío se traduce no sólo en tristeza y abatimiento, sino también en aislamiento y en conciencia de la alteridad, su expresión literaria puede llegar a independizarse por completo de cualquier referente externo. En el capítulo que sigue a la primera descripción de la ciudad brumosa, el sentir de Flavio ya no guarda relación alguna con aquello que contempla. En su malestar, le es indiferente centro o periferia, lluvia o sol. El hastío invade y determina la lógica de sus sensaciones, blindadas al reconocimiento objetivo de la realidad.

Los nuevos afectos son así expresados en una polaridad de signo ambiguo. Por una parte, ya hemos hecho referencia al carácter paradójico del tedio, vinculado simultáneamente al vacío emocional y a la saturación sensitiva. Por otra parte, con frecuencia al entusiasmo sigue el hastío; y al tedio, la energía. Esta polaridad se manifiesta tanto en el cuento de Poe como en Flavio, si bien en Rosalía de Castro la declinación del sentimiento de vacío a la felicidad demuestra ser breve y engañosa. 
Hay otra conclusión especialmente pertinente en el análisis de estos capítulos del Flavio. Aun aceptando la convención biográfica que establece un referente real para la ciudad representada en Flavio, parece claro que Santiago de Compostela no es equiparable, ni en estructura urbanística ni en posición geopolítica, a París o a Londres. Que la autora se refiera a este espacio concediéndole casi el rango de metrópolis no hace sino confirmar la función claramente indiciaria de estos pasajes. Yendo un poco más lejos, la descripción del paisaje urbano en ciertas novelas decimonónicas, especialmente en las anteriores a la consolidación del modelo realista, no ha de verse como una representación fidedigna de los espacios reales, sino como un fenómeno radicalmente sintomático de las nuevas afectividades, que alcanzarán en la ficción literaria una de sus más acendradas expresiones.

Por último, la emergencia de la multitud en estos textos induce a pensar que la expresión del hastío es correlativa de la aparición de nuevos sujetos urbanos en el espacio literario. Mauro Ponzi ha definido la multitud en la ciudad moderna como «un conjunto de soledades de comportamiento uniforme» (Ponzi, 2009: 117). No por casualidad, «The Man of the Crowd» daba comienzo con una máxima de La Bruyere: «Ce grand malheur, de ne pouvoir être seul» (Poe, 2000: 255). La cita inicial describe el tránsito del saber ilustrado sobre la condición humana hacia el ennui del siglo XIX. La infelicidad de no poder estar solo es, en términos decimonónicos, el spleen. El hastío del Flavio rosaliano tiene también su origen en la sensación de estar rodeado de una multitud de la que se reconoce apartado, una multitud que dificulta todo sosiego y toda reflexión —es decir, todo encuentro del sujeto consigo mismo. Pero ¿de qué es representación esa multitud ciega y adónde se dirige? Este vínculo entre subjetividad y afectividad informa de una nueva relación entre el individuo y el mundo, que debe ser remitida a los profundos cambios sociales y políticos que tuvieron lugar en el siglo XIX, cambios de los que participó activamente Rosalía de Castro. Su narrativa emerge como espacio privilegiado para indagar en los vínculos entre espacialidad, subjetividad y percepción, así como en la correlación entre la ficción y la forja de una nueva comunidad sociopolítica. Mostrar estos vínculos demanda un modelo crítico sumamente atento a la configuración verbal de los sentimientos o, si lo preferimos, al sentido literal y literario de los conceptos sensibles; un modelo ajustado, por tanto, a lo que podríamos denominar la vida emocional de las palabras.

Aplicada al estudio de la literatura, la historia de las emociones invita a reflexionar sobre las categorías de conocimiento y sensibilidad que las obras de ficción han ido forjando a lo largo del tiempo. En Flavio, el tedio puede ser visto como un parpadeo en el camino hacia una nueva estética literaria, como vislumbre de concepciones avanzadas de la sociedad y de sus posibilidades - o imposibilidades - de transformación futura. Que el protagonista sea un viajero no hace sino reforzar la voluntad regeneradora de la propuesta literaria de Rosalía de Castro. Pero en la medida en que el ámbito de actuación por ella elegido es la ficción sentimental (y no, por ejemplo, la prosa de 
ideas) no hay que hacerse ilusiones sobre el carácter confiado y literal de su proyecto crítico. Si en su Anatomy of Melancholy (1621) Robert Burton había recomendado viajar al triste como único y duradero remedio para su enfermedad, el viaje ya no podrá curar a Flavio. Pues como ya hemos visto, al paseante moderno que pretenda huir del tedio paseando, el paseo lo devolverá inevitablemente al tedio. Por decirlo de nuevo en palabras de Rosalía de Castro (Follas Novas, 1880), «Este barro mortal que envolve o espírito, / quen o entenderá, Señor?» (Castro, 2004: 40).

\section{BIBLIOGRAFÍA CITADA}

Agamben, Giorgio (1977). Stanze: la parola e il fantasma nella cultura occidentale. Torino: Eunadi.

Bartra, Roger (2004). El duelo de los ángeles. Locura sublime, tedio y melancolía en el pensamiento moderno. Valencia: Pre-textos.

Baudelaire, Charles (1975a). Les Fleurs du Mal, en Claude Pichois (ed.), Oeuvres complètes. Vol. I. Paris: Gallimard, pp. 137-177.

Baudelaire, Charles (1975b). Le Spleen de Paris, en Claude Pichois (ed.), Oeuvres completes. Vol. I. Paris: Gallimard, pp. 275-371.

Benjamin, Walter (1980). Poesía y capitalismo. Iluminaciones II. Madrid: Taurus, 1980.

Carreri, Francesco (2002). Walkscapes. El caminar como práctica estética. Barcelona: Gustavo Gili.

Castro, Rosalía de (1982a). El caballero de las botas azules, en Mauro Armiño (ed.), Obras completas. Vol II. Madrid: Akal, pp. 241-566.

Castro, Rosalía de (1982b). Flavio, en Mauro Armiño (ed.), Obras completas. Vol. III, pp. 13-284. Madrid: Akal, pp. 13-284.

Castro, Rosalía de (2004). Follas novas, en Andrés Pociña y Aurora López eds., Poesía galega completa Vol. II. Santiago de Compostela: Sotelo Blanco.

Compagnon, Antoine (2007). Los Antimodernos. Trad. de Manuel Arranz. Barcelona: Acantilado.

Cunningham, David (2009). «El cuento de la modernidad: Poe, Benjamin y el relato de la metrópoli», en Félix Duque (ed.), Poe. La mala conciencia de la modernidad. Madrid: Círculo de Bellas Artes, pp. 41-78.

Davies, Catherine (1987). Rosalía de Castro no seu tempo.Vigo: Galaxia.

Domínguez, Ramón Joaquín (1848). Diccionario nacional o gran diccionario clásico de la lengua española: el más completo de los léxicos publicados hasta el día. Madrid: Imprenta Nacional. Vol. II.

Fernández, Pura (2005). «La escritura cooperativa: cómo y por qué se construye una novela por entregas en el siglo XIX. Del taller de Enrique Pérez Escrich a la lejía contra los malos libros de Rosalía de Castro», Revista de Estudios Hispánicos. XXXIX, 2, pp. 331-360.

García Negro, María Pilar (1986). «Rosalía á luz de Mara», en Actas do Congreso Internacional de Estudios sobre Rosalía de Castro e o seu tempo. Santiago de Compostela: Consello da Cultura Galega, pp. 73-80.

Gilmore, Michael (1985). American Romanticism and the Marketplace. Chicago: University of Chicago Press.

Ginzburg, Carlo (1989). «Indicios. Raíces de un paradigma de inferencias indiciales», en Mitos, emblemas, indicios. Morfología e Historia. Barcelona: Gedisa, pp.138-175 
Goodstein, Elizabeth S. (2005). Experience without Qualities: Boredom and Modernity. Standford: Stanford University Press.

Gullón, Germán (1986). «El caballero de las botas azules: farsa de las letras decimonónicas», en Actas do Congreso Internacional de estudios sobre Rosalía de Castro e o seu tempo. Santiago de Compostela: Consello da Cultura Galega, pp. 483-491.

Hayes, Kevin J. (2002). «Visual Culture and the Word in Edgar Allan Poe's The Man of the Crowd», Nineteenth-Century Literature. 56, 4, pp. 445-465.

Huguet, Michèle (1984). L'ennui et ses discourses. Paris: Presses Universitaires de France.

Jonard, Norbert (1998). L'Ennui dans la littérature européenne: des origines à l'aube du XXe siècle. Paris: Honoré Champion.

Klibansky, R., Erwin Panofsky y F. Saxl (1964). Saturn and Melancholy. Studies in the History of Natural Philosophy, Religion, and Art. Londres: Nelson.

Koselleck, Reinhardt (2002). The Practice of Conceptual History. Timing History: Spacing Concepts. Stanford: Stanford University Press.

Kuhn, Reinhardt (1976). The Demon of Noontide. Ennui in Western World Literature. Princeton: Princeton University Press.

López Guix, Juan Gabriel (2009). «Sobre la primera traducción de Edgar Allan Poe al castellano». 1611. Revista de Historia de la Traducción / A Journal of Translation History / Revista d'Història de la Traducció, III. http://www.traduccionliteraria.org/1611/art/ lopezguix 2.htm.

Lozano de la Pola, Ana (2008). «El caballero de las botas azules de Rosalía de Castro como artefacto (meta)literario», en María Cecilia Trujillo Maza et alii (eds.) Lectores, editores y audiencia: la recepción en la literatura hispánica. Vigo: Editorial Academia del Hispanismo.

March, Kathleen (1994). De musa a literata. El feminismo en la narrativa de Rosalía de Castro. Sada: Ediciós do Castro.

Poe, Edgar Allan (1984). Articles and Marginalia, en G. R. Thompson (ed.), Essays and Reviews. New York: The Library of America, pp. 1223-1472.

Poe, Edgar Allan (2000). «The Man of the Crowd», en John S. Whitley (ed.), Tales of Mistery and Imagination. Hertfordshire: Wordsworth, 2000.

Ponzi, Mauro (2009). «Ebriedad y terror. La multitud en Poe, Baudelaire y Benjamin», en Félix Duque (ed.), Poe: la mala conciencia de la modernidad. Madrid: Círculo de Bellas Artes.

Sebold, Russell P. (1989). «Sobre el nombre español del dolor romántico», en David Thatcher Gies (ed.), El Romanticismo. Madrid: Taurus, pp. 98-109.

Serés, Guillermo (1994). «El concepto de fantasía, desde la estética clásica hasta la dieciochesca», Anales de Literatura Española. 10, pp. 208-36.

Steiner, George (1977). «El Gran Ennui», en El castillo de Barbazul. Trad. de Hernando Valencia Goelkel. Madrid: Guadarrama, pp. 9-30.

Svendsen, Lars (2006). Filosofía del tedio. Trad. de Carmen Montes Cano. Barcelona: Tusquets. Villanueva, Darío (1991). El polen de ideas. Teoría, Crítica, Historia y Literatura comparada. Barcelona: Promociones y Publicaciones Universitarias.

Wittgenstein, Ludwig (1988). Investigaciones filosóficas. Trad. de A. García Suárez y C.U. Moulines. Barcelona: Crítica.

Zima, Pierre (1980). L’Ambivalence romanesque. Paris: Le Sycomore.

Zima, Pierre (1985). Manuel de Sociocritique. Paris: Picard. 